\title{
[Leu]Enkephalin Enhances Active Avoidance Conditioning in Rats and Mice
}

Patricia H. Janak, Ph.D., Jennifer J. Manly, and Joe L. Martinez, Jr., Ph.D.

The effects of intraperitoneal (IP) administration of the endogenous opioid peptide, [Leu]enkephalin (LE), on avoidance conditioning in rodents were investigated. At a dose of $30 \mu \mathrm{g} / \mathrm{kg}(I P)$, LE enhanced acquisition of $a$ one-way step-through active avoidance response when administered 2 minutes before training to Swiss Webster mice. [Leu]enkephalin produced a U-shaped dose-response function because both lower and higher doses of $L E$ did not affect avoidance responding. [Leu]enkephalin-induced enhancement of avoidance acquisition was also observed in Sprague-Dawley rats; the intraperitoneal injection of $10 \mu \mathrm{g} / \mathrm{kg} L E$, administered 5 minutes before training, enhanced acquisition of $a$ jump-up one-way active avoidance response. When administered to Sprague-Dawley rats immediately after training, LE (30 $\mu \mathrm{g} / \mathrm{kg} I P)$ enhanced jump-up avoidance responding at test 24 hours after peptide injection. Previously, we found LE to impair acquisition in the same tasks in both rats and mice, also at microgram doses, and also in a U-shaped manner. Thus, LE can either enhance or impair learning within the same species and the same task; these findings are in agreement with recent theoretical proposals regarding the nature of compounds, such as LE, that modulate learning and memory. [Neuropsychopharmacology 10:53-60, 1994]
KEY WORDS: Enkephalin; Aversive conditioning; Acquisition; Retention; Learning; Memory; Rat; Mouse

In 1981, McGaugh and Martinez designated neurohormones that affect learning and memory as learning modulatory hormones. Since that time, empirical research has determined the defining characteristics of endogenous substances that modulate learning (Martinez et al. 1991a; Koob 1987; Gold 1989; McGaugh 1989). Two of these defining characteristics are that 1 ) the dose-response functions produced by modulatory substances are U-shaped, rather than hyperbolic, and 2) each modulatory substance has the ability to either

From the Department of Psychology, University of California, Berkeley, California 94720.

Address correspondence to: Patricia H. Janak, Ph.D., Department of Psychology, 3210 Tolman Hall, University of California, Berkeley, CA 94720.

Received June 25, 1993; revised September 29, 1993; accepted October 12, 1993. improve or worsen learning and memory (Martinez et al. 1991a; Schulteis et al. 1990; Schulteis and Martinez 1992a; Gold 1989). These characteristics are derived from discovering commonalities among the considerable list of endogenous hormones that influence learned performance in experimental animals.

Opioid peptides, such as $\beta$-endorphin, dynorphin, [Met]enkephalin (ME), and [Leu]enkephalin (LE), are endogenous neuropeptides that appear to be learning and memory modulatory substances. For each of these opioid peptides, the characteristic U-shaped dose-effect function has been demonstrated (for examples, see Martinez et al. 1981, 1991a; Schulteis et al. 1988; Colombo et al. 1992; Martinez and Rigter 1980), thus fulfilling the first of the defining characteristics for a modulatory substance.

The second defining characteristic of bidirectional memory effects of modulatory substances is less clear for these opioid peptides. For example, the endogenous opioid peptide LE, when administered to a variety of species in a multitude of tasks, most frequently impairs learning (Rigter et al. 1980a, 1980b, 1981; Izquierdo et 
al. 1980; Izquierdo and Dias 1981; Martinez et al. 1981, 1984, 1985a, 1985b, 1988, 1990; Martinez and Rigter 1982; Introini et al. 1985; Dana and Martinez 1986; Linden and Martinez 1986; Schulteis et al. 1988, 1990; Patterson et al. 1989; Janak and Martinez 1990; Sandi et al. 1990; Schulteis and Martinez 1992b). [Leu]enkephalin impairs active avoidance acquisition in mice (Martinez et al. 1985b; Dana and Martinez 1986; Schulteis et al. 1988; Janak and Martinez 1990) and in rats (Rigter et al. 1980a, 1980b, 1981; Martinez and Rigter 1982; Martinez et al. 1985a). [Leu]enkephalin also impairs retention of active avoidance conditioning in mice (Dana and Martinez 1986; Schulteis and Martinez 1992b) and rats (Izquierdo et al. 1980; Izquierdo and Dias 1981).

In contrast, some studies report that LE enhances learning and memory. [Leu]enkephalin attenuates $\mathrm{CO}_{2-}$ induced amnesia for a passive avoidance response in rats (Rigter 1978) and enhances retention of a passive avoidance response in rats (Martinez et al. 1981). Thus, a small number of studies suggest that LE enhances learning and memory in animals.

As with LE, the most frequently observed effect of exogenous administration of other opioid peptides is learning and memory impairment (see Schulteis et al. 1990; Martinez et al. 1991a for review), although a few cases of enhancement were observed. For example, although ME is reported to impair acquisition (Rigter et al. 1980a) and retention (Introini et al. 1985; Izquierdo and Dias 1981) of avoidance conditioning in rats and mice, other reports indicate that ME enhances acquisition of Y-maze (Martinez et al. 1984) and complex maze (Kastin et al. 1976) learning and delays extinction of a pole-jump response (de Wied et al. 1978) in rats. [Met]enkephalin also enhances retention of and attenuates $\mathrm{CO}_{2}$-induced amnesia for passive avoidance conditioning in rats (Martinez et al. 1981; Rigter 1978).

Because the methodologies (task and injection route; strain and species used) varied between these studies of the learning and memory effects of enkephalins, it is difficult to directly compare the results. Thus, the evidence indicates that some enkephalins either enhance or impair learned behavior; however, it has yet to be demonstrated that enkephalins are capable of producing enhancement and impairment under the same conditioning parameters. The following studies demonstrate that the pre- or posttraining intraperitoneal injection of LE enhances active avoidance conditioning in two separate species; in each case, the task parameters were identical to those in which we have previously demonstrated LE-induced learning impairment (Janak and Martinez 1990; Weinberger et al. 1989). This demonstration supports current views that the behavioral effect of an exogenously administered opioid may depend upon the basal state of the subject, rather than task parameters alone (Martinez et al. 1991a; Schulteis and Martinez 1992a).

\section{GENERAL METHODS}

\section{Subjects}

Food and water were available ad lib; the animals were maintained on a standard 12-hour light/12-hour dark schedule with lights on at 7 A.M. Newly arrived animals were allowed at least 4 days to acclimate before any experimental procedures were conducted. Housing conditions were in accord with National Institutes of Health $(\mathrm{NIH})$ guidelines, and all experimental procedures were approved in advance by the Animal Care and Use Committee at the University of California, Berkeley.

\section{Drugs}

[Leu]enkephalin (Tyr-Gly-Gly-Phe-Leu), obtained from Bachem (Torrance, CA), was dissolved in $0.9 \%$ saline and administered via intraperitoneal injection in a volume of $1 \mathrm{ml} / 100 \mathrm{~g}$ for mice and $1 \mathrm{ml} / \mathrm{kg}$ for rats. The experimenter was unaware of the specific treatment a subject received until testing was concluded.

\section{Procedures}

The subjects were brought into the testing room a minimum of 3 hours before conditioning began. All experimental procedures occurred between the hours of $11 \mathrm{AM}$ and 4 PM. A tensor lamp provided dim lighting, and a fan provided background noise.

\section{Data Analysis}

Planned single degree-of-freedom comparisons between the treatment (LE-injected) and control (vehicleinjected) groups were conducted. To control for Type I error, the Bonferroni correction method was applied to adjust the alpha level for each experiment (Keppel 1991); family-wise error was set to .10. Because a limited number of animals may be used in each day's study, completion of a full dose-response curve required combining data across consecutive experimental days. Because a saline-injected control group was included in each experimental session, pooling of the saline-treated subjects created a larger sample size in the saline-treated groups than in the drug-treated groups. 


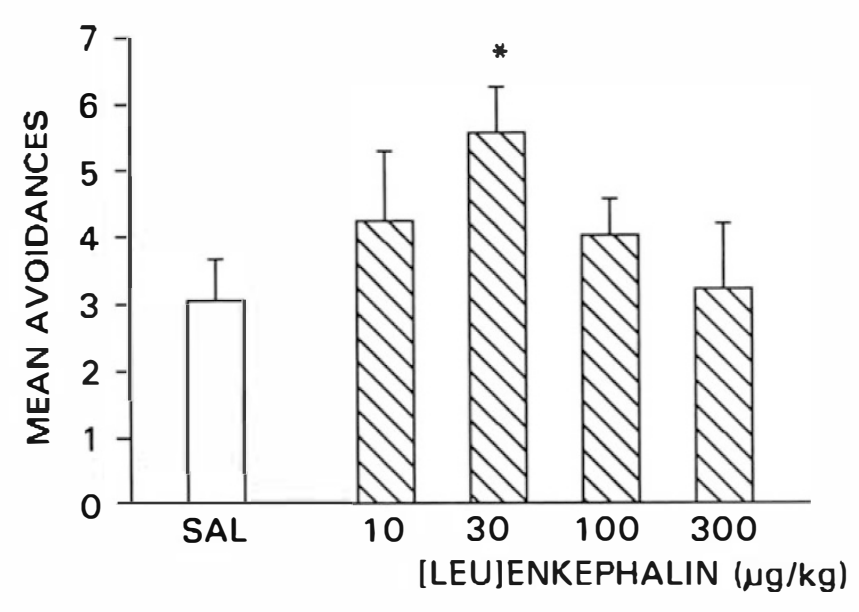

Figure 1. Effect of pretraining LE administration on active avoidance acquisition in Swiss Webster mice. [Leu]enkephalin $(30 \mu \mathrm{g} / \mathrm{kg})$ enhanced the mean number of avoidance responses made in 14 trials. Sample sizes are as follows: saline, $n=19$; $10-\mu \mathrm{g} / \mathrm{kg} \mathrm{LE}, n=9 ; 30-\mu \mathrm{g} / \mathrm{kg}$ LE, $n=13 ; 100-\mu \mathrm{g} / \mathrm{kg} \mathrm{LE}, n=$ $19 ; 300-\mu \mathrm{g} / \mathrm{kg}, n=5 .{ }^{\star} p<.05$.

\section{EXPERIMENT 1}

This experiment investigated the effect of pretraining LE administration on one-way step-through active avoidance conditioning in mice.

\section{Methods}

Subjects. Male Swiss Webster mice, weighing between 29 and $36 \mathrm{~g}$, were obtained from Benton-Kingman and were housed three to a cage.

Apparatus and Procedure. The avoidance chamber consisted of two trough-shaped compartments: a smaller well-lit compartment $(10 \times 10 \times 10 \mathrm{~cm})$, made of white acrylic, separated by a black acrylic sliding door from a metal-floored shock compartment. The shock compartment $(23 \times 10 \times 10 \mathrm{~cm})$ was constructed of black acrylic, except for the metal floor. Peptide (10, 30, 100, or $300 \mu \mathrm{g} / \mathrm{kg}$ ) or saline was administered 2 minutes prior to avoidance training. On the first trial, animals were placed in the shock compartment facing away from the closed entrance to the lit compartment. After $10 \mathrm{sec}-$ onds, the doorway separating the two compartments was opened and the animals received a mild footshock $(390 \mu \mathrm{A})$ and were allowed to escape into the lit compartment. On all subsequent trials, the animals were placed facing away from the lit compartment and allowed 10 seconds within which they could successfully avoid footshock by crossing through the open doorway into the smaller lit compartment. Failure to avoid resulted in application of footshock. All mice that did not escape the footshock within 20 seconds were placed into the smaller lit compartment by the experimenter. Mice received a total of 14 trials with 20-second intertrial intervals. The number of avoidances made by each animal was recorded and used to measure performance. All subjects completed training and were included in the final analysis of the data.

\section{Results}

Pretraining LE enhanced acquisition of one-way active avoidance responding in mice. As seen in Figure 1, a $30-\mu \mathrm{g} / \mathrm{kg}$ dose of LE significantly enhanced acquisition of the active avoidance task in mice as compared with saline-treated control animals $(F[1,30]=6.94, p<.02)$, whereas mice receiving doses of $10(F[1,26]=1.01, p$ $=.33), 100(F[1,36]=1.30, p=.26)$, and $300 \mu \mathrm{g} / \mathrm{kg} \mathrm{LE}$ $(F[1,22]=.01, p=.91)$ did not differ from saline control animals. The dose-response function produced is an inverted $U$ shape, as indicated by a significant quadratic trend component: $(F[1,60]=6.28, p<.02)($ Keppel 1991).

\section{EXPERIMENT 2}

This experiment investigated the effects of pretraining LE administration on acquisition of active avoidance responding in rats. The task used differs from the stepthrough active avoidance task in that a distinctive conditioned stimulus (CS) (houselight) signals the unconditioned stimulus (US) (footshock), and jumping, rather than forward locomotion, is required for shock escape or avoidance. In addition, the jump-up avoidance apparatus is automated, thus eliminating the need for intertrial experimenter handling, as required by the stepthrough one-way avoidance apparatus.

\section{Methods}

Subjects. Male Sprague-Dawley rats, weighing between 260 and $300 \mathrm{~g}$, were obtained from Simonsen and were singly housed.

Apparatus and Procedure. The shelf-jump conditioning chamber (Lafayette Instruments, Lafayette, IN) was a 23- $\times 21-\mathrm{cm}$ rectangle with two opposing lucite walls and a third metal wall (all $21 \mathrm{~cm}$ tall). The fourth wall contained a rectangular metal compartment, that, when open, was recessed $12.5 \mathrm{~cm}$ from the chamber proper, $21 \mathrm{~cm}$ in length, and elevated $9 \mathrm{~cm}$ from the floor of the chamber. When the shelf was in the closed position, the back wall of the platform was brought flush with the two side lucite walls, appearing then as a con- 


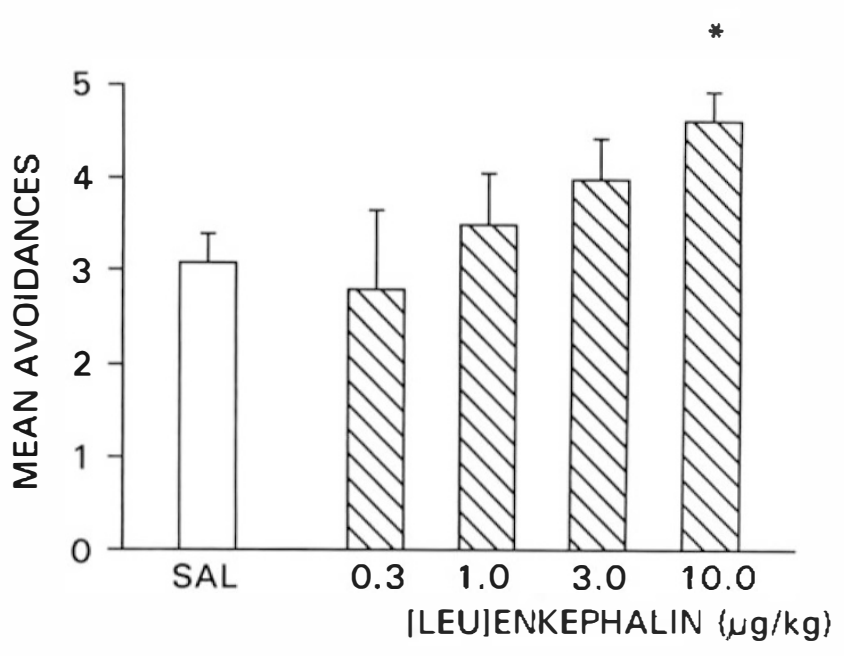

Figure 2. Effect of pretraining LE administration on active avoidance acquisition in Sprague-Dawley rats. [Leu]enkephalin $(10 \mu \mathrm{g} / \mathrm{kg})$ enhanced the mean number of avoidance responses made in eight trials. Sample sizes are as follows: saline, $n=13 ; 0.3-\mu \mathrm{g} / \mathrm{kg} \mathrm{LE}, n=5 ; 1.0-\mu \mathrm{g} / \mathrm{kg} \mathrm{LE}, n=6 ; 3.0-\mu \mathrm{g} / \mathrm{kg}$ LE, $n=7 ; 10-\mu \mathrm{g} / \mathrm{kg}, n=8 .{ }^{*} p<.01$.

tinuous metal wall. The floor of the chamber consisted of a steel-rod grid floor, through which a constant current footshock was delivered. A houselight was mounted $15 \mathrm{~cm}$ from the floor on the metal wall opposite the shelf. A pressure-sensitive switch under the platform registered jump-up responses. All equipment was controlled by an Apple Ile computer (Apple Computers, Cupertino, CA) interfaced with solid state control equipment (Lafayette Instruments).

Peptide $(.3,1,3$, or $10 \mu \mathrm{g} / \mathrm{kg})$ or saline was administered 5 minutes before the first acquisition trial. On trial one, each rat was placed on the floor of the chamber, with the shelf in the closed position. Ten seconds after the initiation of the trial, three events occurred simultaneously: 1) the back wall of the platform withdrew, exposing the platform; 2) the CS (houselight) came on; 3) and a footshock of $290 \mu \mathrm{A}$ was delivered to the floor of the chamber. The footshock (US) and CS remained on for 30 seconds or until the subject escaped by jumping up onto the exposed platform. Following a 30-second intertrial interval, the back wall of the platform moved forward into the "closed" position, gently depositing the rat onto the steel-rod floor and initiating the next trial. For the following 7 trials, the platform was exposed and the CS came on 10 seconds prior to footshock (US) onset; therefore, the subject could avoid footshock by jumping onto the exposed platform prior to shock initiation. Maximum trial length was 40 seconds. Subjects that did not escape the footshock for two or more trials were excluded from the study (5\%); exclusion was uniform across treatment groups.

\section{Results}

[Leu]enkephalin administration enhanced acquisition of jump-up avoidance conditioning. As illustrated in Figure 2, the pretraining administration of $10 \mu \mathrm{g} / \mathrm{kg} \mathrm{LE}$ to rats significantly enhanced acquisition of jump-up avoidance responding, as indicated by a higher mean number of avoidance responses relative to saline-treated control rats $(F[1,19]=10.84, p<.004)$. Pretraining administration of $0.3,1.0$, and $3.0 \mu \mathrm{g} / \mathrm{kg}$ LE did not affect acquisition $(0.3 \mu \mathrm{g} / \mathrm{kg}$ LE: $F[1,16]=.15, p=.71 ; 1.0$ $\mu \mathrm{g} / \mathrm{kg}$ LE: $F[1,17]=.51, p=.49 ; 3.0 \mu \mathrm{g} / \mathrm{kg}$ LE: $F[1,18]$ $=3.04, p=.10$ ).

\section{EXPERIMENT 3}

The previous two experiments demonstrated that the pretraining injection of LE enhances avoidance response acquisition. This experiment investigated the effects of posttraining LE injection on jump-up avoidance responding in a 3-day paradigm in rats.

\section{Methods}

Subjects. Male Sprague-Dawley rats, weighing between 230 and $280 \mathrm{~g}$, were obtained from Harlan Sprague-Dawley and were singly housed.

Apparatus and Procedure. The apparatus was the same as that used in Experiment 2. Conditioning consisted of three consecutive daily sessions. On day 1 , each rat was given one escape-only trial in which the CS (houselight) onset and footshock (US) $(290 \mu \mathrm{A})$ onset were paired for 30 seconds or until the subject jumped up onto the platform, thus terminating the CS and the shock. Each subject was then removed from the apparatus, injected with LE ( 3 or $30 \mu \mathrm{g} / \mathrm{kg}$ ) or vehicle, and replaced into its home cage. The procedure on day 2 was exactly the same as on day 1 . On day 3 , each rat received 12 trials in which the shelf was exposed 10 seconds prior to footshock onset, allowing the subject to either avoid or escape the shock, as described in Experiment 2. Subjects that did not learn the escape response on day 1 or 2 were excluded from the study $(10 \%)$; exclusion was uniform across treatment groups.

\section{Results}

The results indicated that 2 days of posttraining LE administration enhanced acquisition of the jump-up avoidance response, as measured by avoidance performance on day 3. Analysis of the data revealed that $30 \mu \mathrm{g} / \mathrm{kg}$ $\operatorname{LE}(F[1,22]=8.01, p<.01)$, but not $3 \mu \mathrm{g} / \mathrm{kg} \mathrm{LE}(F[1,21]$ $=.32, p=.58$ ) enhanced performance on day 3 , as evi- 


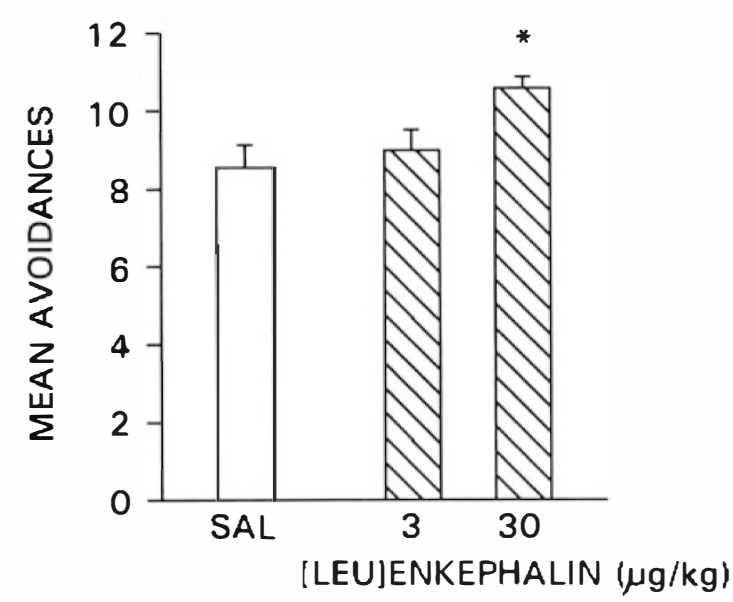

Figure 3. Effect of posttraining LE administration on active avoidance retention in Sprague-Dawley rats. [Leu]enkephalin $(30 \mu \mathrm{g} / \mathrm{kg})$ enhanced the mean number of avoidance responses made in the 12-trial retention test. Samples sizes are as follows: saline, $n=13 ; 3.0-\mu \mathrm{g} / \mathrm{kg} \mathrm{LE}, n=10 ; 30-\mu \mathrm{g} / \mathrm{kg}$, $n=11 .{ }^{\star} p<.01$.

denced by a higher mean number of avoidance responses when compared to saline-treated control animals. These data are illustrated in Figure 3.

\section{DISCUSSION}

In the present study, LE dose dependently enhanced one-way active avoidance acquisition in Swiss Webster mice when administered prior to training (Experiment 1). These results were extended to rats. In Experiment 2 , we found that the pretraining administration of LE to Sprague-Dawley rats enhanced acquisition of jumpup active avoidance conditioning. In addition, the posttraining administration of LE to Sprague-Dawley rats enhanced retention of jump-up active avoidance conditioning (Experiment 3 ). The only previously reported instances of learning enhancement produced by LE were found with passive avoidance conditioning; the present report represents three instances of LE-induced learning enhancement in active avoidance tasks. Because extensive previous study demonstrated that LE most frequently impairs learning and memory when administered either pretraining or posttraining to both rats (Rigter et al. 1980a, 1980b, 1981; Martinez and Rigter 1982; Martinez et al. 1985a) and mice (Martinez et al. 1985b; Dana and Martinez 1986; Schulteis et al. 1988; Janak and Martinez 1990), these results show that LE can both enhance and impair acquisition of active avoidance conditioning. Importantly, the enhancement of avoidance responding produced by LE in this study was observed under task conditions in which LE usually produces impaired performance. These results therefore demonstrate that it is not the nature of the behavioral task that determines the direction of the effect of this peptide, but perhaps other variables such as the basal stress levels of subjects play a role in determining the behavioral effect of LE.

The learning and memory enhancement produced by LE in the present study is similar in two respects to the LE-induced learning impairment that we have observed previously in these same tasks. First, the dose range for both enhancement and impairment is similar. For example, in the mouse, a $30-\mu \mathrm{g} / \mathrm{kg}$ dose of LE enhanced acquisition (Experiment 1), whereas this same dose impaired acquisition in previous studies (Schulteis et al. 1988; Schulteis and Martinez 1990). Likewise, in the rat, we found that pretraining administration of a $10-\mu \mathrm{g} / \mathrm{kg}$ dose of LE enhanced acquisition of a jump-up avoidance response (Experiment 2), whereas in a previous study, pretraining administration of 1 or $3 \mu \mathrm{g} / \mathrm{kg}$ LE (Weinberger et al. 1989), or $10 \mu \mathrm{g} / \mathrm{kg} \mathrm{LE} \mathrm{(Martinez}$ and Rigter 1982; Rigter et al. 1981), impaired jump-up avoidance learning. The dose of LE $(30 \mu \mathrm{g} / \mathrm{kg})$ that enhanced jump-up avoidancelearning following its posttraining administration to rats in the present study is also within the 1 - to $100-\mu \mathrm{g} / \mathrm{kg}$ dose range. These results reveal that the direction of LE's avoidance conditioning effects cannot be accounted for simply on the basis of differing doses.

The second similarity between LE-produced learning enhancement and impairment is that the doseresponse functions produced in both cases are $\mathrm{U}$ shaped. Thus, we found that a dose of $30 \mu \mathrm{g} / \mathrm{kg}$ LE enhanced acquisition in mice, whereas doses both lower and higher had no effect. This quadratic-shaped doseresponse function, although opposite in direction, also is produced in experiments in which LE impairs avoidance conditioning (Martinez et al. 1988; Schulteis et al. 1988). U-shaped, dose-response curves commonly are produced by treatments that modulate learning and memory, whether they are enhancing or impairing (see Martinez et al. 1991a; Schulteis and Martinez 1992a for discussion of U-shaped curves and memory). Therefore, at least in mice, the conditioning enhancement and impairment produced by LE are similar to one another. The LE dose-response functions obtained in rats in the present study were not extended beyond the doses found to significantly affect avoidance responding and therefore cannot lend support to these results obtained in mice.

Our results are similar to the effects of the endogenous opioid peptides $\mathrm{ME}$ and $\beta$-endorphin on learning. Although some studies report impairment of aversive conditioning (Martinez and Rigter 1980, 1982; Izquierdo et al. 1980; Zhang et al. 1987), others report 
enhancement (de Wied et al. 1978; Kovacs et al. 1981; Kovacs and de Wied 1981; Martinez et al. 1984). None of these studies in which $\beta$-endorphin or ME enhanced learning and memory are easily compared to those studies in which the peptides produced impairment, as the studies did not use identical training and testing procedures. For example, $\beta$-endorphin impaired retention of an inhibitory avoidance response when administered intraperitoneally to rats in a study by Martinez and Rigter (1980), whereas subcutaneous administration of the same peptide enhanced rats' retention for an inhibitory avoidance response in a study by Kovacs and de Wied (1981). It is notable that the studies reported here were conducted identically to previous studies in which we found LE to impair learning and memory.

What factors might have contributed to the results obtained in the present study? These results are not due to circadian or seasonal effects, because the time of day and year that testing occurred is similar to that of studies in which LE-induced impairment was observed previously by us in both rats and mice. In addition, the results of additional studies conducted by the experimenters indicate that the present results cannot be attributed to differences in experimenter handling. Indeed, the automated shelf-jump avoidance apparatus used for Experiments 1 and 2 minimized experimenter handling.

However, although the avoidance acquisition enhancement observed in Experiment 1 was conducted in Swiss Webster mice, the strain of mice that we commonly use, the subjects came from a different commercial breeder than used by us in previous studies. In fact, we observed that the saline-treated mice included in Experiment 1 performed more poorly than saline-treated mice from some other breeders. Factors that lead to opposite effects in the same strain, but different suppliers, are not known at this time. The albino rat subjects used for Experiments 2 and 3 were obtained from the same breeders we commonly use; however, the subjects were housed and the experiments were conducted in a different building than used by us in previous studies. How different buildings contribute to opposite pharmacologic effects is unknown. However, when compared to saline-treated subjects in our previous study of opioid effects on jump-up avoidance acquisition (Weinberger et al. 1989), the saline-treated rats from Experiment 2 performed more poorly, suggesting that basal arousal levels of rats in the present studies may have been affected by the housing environment.

The present study thus suggests that determination of the overall direction of effect of a given pharmacologictreatment is complex. Previous research with the classic leaming and memory modulatory treatments, adrenocorticotrophic hormone (ACTH) and epinephrine, specified variables that may impact the direction of the effect of pharmacologic treatments on learning and memory. In the studies of Gold and van Buskirk $(1975,1976)$, either enhancement or impairment of retention of an inhibitory avoidance response could be obtained with the same hormone by manipulating the dose and keeping the footshock level constant or by manipulating the footshock level and keeping the dose constant. Similar results were obtained following the posttraining administration of dynorphin $1-17$ to rats: dynorphin enhanced retention of passive avoidance conditioning when subjects were trained with weak footshock, and dynorphin impaired retention of passive avoidance conditioning when subjects were trained with strong footshock (del Cerro and Berrell 1990). These studies indicate that a hormone usually released as a consequence of arousal or stress also may modulate learning. In addition, these studies indicate that factors that influence arousal levels in animals may have an impact on the conditioning effects of exogenously administered stress hormones, such that the influence of a particular hormone on memory formation could vary depending on experimental conditions that alter the concentration of the hormone available for receptor action (Schulteis and Martinez 1992a; Martinez et al. 1991a, 1991b; McCarty and Gold 1981; Gold 1989; McGaugh 1989).

[Leu]enkephalin is similar to ACTH and epinephrine in that it is a hormonelike substance that is released into the circulation in response to arousal or stress (DiGiulio et al. 1978; Hanbauer et al. 1982; Hexum et al. 1980; Schultzberg et al. 1978), and it alters learned performance. Thus, as with ACTH and epinephrine, factors that influence the arousal of experimental subjects may alter the effects of exogenous administration of LE. Factors that were not explicitly manipulated in our studies, such as the commercial supplier and the housing environment, could have been important determinants of stress levels in our subjects. Thus, one possibility is that the basal arousal state (and, thus, the basal levels of endogenous circulating LE) of our subjects helped determine the direction of effect of LE on avoidance conditioning. Interestingly, direct evidence that stress affects memory via an opioid-dependent mechanism is provided by the finding that posttraining restraint stress strain-specifically alters retention of passive avoidance conditioning in mice, and these effects are reversed by naloxone(Castellano and PuglisiAllegra 1983).

The present results in which the endogenous opioid peptide LE enhances learning, together with the more typical previous results in which LE impairs learning, provide evidence that fulfills both defining characteristics of a learning modulatory substance, as first described by McGaugh and Martinez (1981) and later extended (Martinez et al. 1991a; Schulteis and Martinez 1992a). Thus, LE can eitherenhance or impair learning and memory, independent of task specifics such as 
the response requirement or the route of peptide administration, and the function produced by LE administration is $U$ shaped, regardless of whether the peptide is enhancing or impairing behavior. Therefore, LE provides a good example of learning and memory modulation by endogenous neuropeptides.

\section{ACKNOWLEDGMENT}

This work was supported by Public Health Service Grant DA 04195 to JLM from the National Institute on Drug Abuse.

\section{REFERENCES}

Castellano C, Puglisi-Allegra S (1983): Strain-dependent modulation of memory by stress in mice. Behav Neural Biol 38:133-138

Colombo PJ, Martinez JL Jr, Bennett EL, Rosensweig MR (1992): Kappa opioid receptor activity modulates memory for peck-avoidance training in the two-day-old chick. Psychopharmacology 108:235-240

Dana RC, Martinez JL Jr (1986): Long-term effects of leucineenkephalin on active avoidance responding in mice. Behav Neurosci 100:814-824

de Wied D, Bohus B, van Ree JM, Urban I (1978): Behavioral and electrophysiological effects of peptides related to lipotropin (B-LPH). J Pharmacol Exp Ther 204:570-580

del Cerro S, Berrell J (1990): Dynorphin 1-17 can enhance or impair retention of an inhibitory avoidance response in rats. Life Sci 47:1453-1462

DiGiulio AM, Yang HYT, Lutold B, Fratta W, Hong J, Costa $E$ (1978): Characterization of enkephalin-like material extracted from sympathetic ganglia. Neuropharmacology 17:989-992

Gold PE (1989): Neurobiological features common to memory modulation by many treatments. Animal Learn Behav 17:94-100

GoldPE, van Buskirk RB (1975): Facilitation of time-dependent memory processes with posttrial epinephrine injection. Behav Biol 13:145-153

Gold PE, van Buskirk RB (1978): Effects of posttrial hormone injections on memory processes. Horm Behav 7:509-517

Hanbauer I, Kelly GD, Saiani L, Yang H-YT (1982): Metenkephalin-like peptides of the adrenal medulla: Release by nerve stimulation and functional implications. Peptides 3:469-473

Hexum TD, Yang Y-YT, Costa E (1980): Biochemical characterization of enkephalin-like immunoreactive peptides of adrenal glands. Life Sci 27:1211-1216

Introini IB, McGaugh JL, Barrati CM (1985): Pharmacological evidence of a central effect of naltrexone, morphine, and beta-endorphin and a peripheral effect of met- and leuenkephalin on retention of an inhibitory response in mice. Behav Neural Biol 44:434-446

Izquierdo I, Dias RD (1981): Retrograde amnesia caused by met-, leu-, and des-tyr-met-enkephalin in the rat and its reversal by naloxone. Neurosci Lett 22:189-193
Izquierdo I, Paiva ACM, Elisabetsky E (1980): Post-training intraperitoneal administration of leu-enkephalin and $\beta$-endorphin causes retrograde amnesia for two different tasks in rats. Behav Neural Biol 28:246-250

Janak PH, Martinez JL Jr (1990): Only tyrosine-containing metabolites of [Leu]enkephalin impair active avoidance conditioning in mice. Pharmacol Biochem Behav 37:655-659

Kastin AJ, Scollan EL, King MG, Schally AV, Coy DH(1976): Enkephalin and a potent analog facilitate maze performance after intraperitoneal administration in rats. Pharmacol Biochem Behav 5:691-695

Keppel G (1991): Design and Analysis: A Researcher's Handbook, 2nd ed. Englewood Cliffs, NJ, Prentice-Hall

Koob GF (1987): Neuropeptides and memory. In Iversen LL, Iversen SD, Snyder SH(eds), Handbook of Psychopharmacology Vol 19: New Directions in Behavioral Pharmacology. New York, Plenum Press, pp 531-573

Kovacs GL, de Wied D (1981): Endorphin influences and memory. In Martinez JLJr, Jensen RA, Messing RB, Rigter $\mathrm{H}$, McGaugh JL (eds), Endogenous Peptides and Learning and Memory Processes. New York, Academic Press, pp 231-247

Kovacs GL, Bohus B, de Wied D (1981): Retention of passive avoidance behavior in rats following alpha and $\gamma$-endorphin administration: Effects of postlearning treatments. Neurosci Lett 22:79-82

Linden D, Martinez JL Jr (1986): Leu-enkephalin impairs memory of an appetitive maze response in mice. Behav Neurosci 100:33-38

Martinez JL Jr, Rigter H (1980): Endorphins alter acquisition and consolidation of an inhibitory avoidance response in rats. Neurosci Lett 18:197-201

Martinez JL Jr, Rigter H (1982): Enkephalin actions of avoidance conditioning may be related to adrenal medullary function. Behav Brain Res 6:289-299

Martinez JL Jr, Rigter H, Jensen RA, Messing RB, Vasquez BJ, McGaugh JL (1981): Endorphin and enkephalin effects on avoidance conditioning: The other side of the pituitaryadrenal axis. In Martinez JL Jr, Jensen RA, Messing RB, Rigter H, McGaugh JL (eds), Endogenous Peptides and Learning and Memory Processes. New York, Academic Press, pp 305-324

Martinez JL Jr, Olson K, Hilston C (1984): Opposite effects of met-enkephalin and leu-enkephalin on a discriminated shock avoidance task. Behav Neurosci 98:487-495

Martinez JL Jr, Conner P, Dana RC (1985a): Central versus peripheral actions of leu-enkephalin on acquisition of a one-way avoidance response in mice. Brain Res 327:37-43

MartinezJLJr, de GraafJS, Chavkin C, Dana RC (1985b): Leuenkephalin actions on avoidance conditioning are mediated by a peripheral opioid mechanism. Life Sci 37:23452353

Martinez JL Jr, Weinberger SB, Schulteis G (1988): Enkephalins and learning and memory: A review of evidence for a site of action outside the blood-brain barrier. Behav Neural Biol 49:192-221

Martinez JL Jr, Janak PH, Weinberger SB, Schulteis G, Derrick BE (1990): Enkephalin influences on behavioral and neural plasticity: Mechanisms of action. In Erinoff L (ed), Neurobiology of Drug Abuse: Learning and Memory. 
Rockville, MD, National Institute on Drug Abuse Research Monograph pp. 48-78

Martinez JL Jr, Schulteis G, Weinberger SB (1991a): How to increase and decrease the strength of memory traces: The effects of drugs and hormones. In Martinez JL Jr, Kesner $\mathrm{R}$ (eds), Learning and Memory: A Biological View. New York, Academic Press, pp 149-198

Martinez JL Jr, Weinberger SB, Janak PH, Schulteis G, Shibanoki S, Ishikawa K (1991b): Peripheral signaling of the brain: How hormones influence learning and memory. In Frederickson RCA, McGaugh JL, Felten DL (eds), Peripheral Signaling of the Brain: Role in Neural-Immune Interactions, Learning and Memory. Toronto, Hogrefe and Huber, pp 365-378

McCarty R, Gold PE (1981): Plasma catecholamine: Effects of footshock level and hormonal modulators of memory storage. Horm Behav 15:168-182

McGaugh JL (1989): Involvement of hormonal and neuromodulatory systems in the regulation of memory storage. Annu Rev Neurosci 12:255-287

McGaugh JL, Martinez JL Jr (1981): Learning modulatory hormones: An introduction to endogenous peptides and learning and memory processes. In Martinez JL Jr, Jensen RA, Messing RB, Rigter H, McGaugh JL (eds), Endogenous Peptides and Leaming and Memory Processes. New York, Academic Press, pp 1-3

Patterson TA, Schulteis G, Alvarado MO, Martinez JL Jr, Bennett EL, Rosenzweig MR, Hruby VJ (1989): Influence of opioid peptides on memory formation in the chick. Behav Neurosci 103:429-437

Rigter H (1978): Attenuation of amnesia in rats by systemically administered enkephalins. Science 200:83-85

Rigter H, Hannan TJ, Messing RB, Martinez JL Jr, Vasquez BJ, Jensen RA, Veliquette J, McGaugh JL (1980a): Enkephalins interfere with acquisition of an active avoidance response. Life Sci 26:337-345

Rigter H, Jensen RA, Martinez JL Jr, Messing RB, Vasquez B J, Liang KC, McGaugh JL (1980b): Enkephalin and fear- motivated behavior. Proc Natl Acad Sci USA 77:37293732

Rigter H, Dekker I, Martinez JL Jr (1981): A comparison of the ability of opioid peptides and opiates to affect active avoidance conditioning in rats. Reg Pept 2:317-322

Sandi C, Borrell J, Guaza C (1990): Administration of leuenkephalin impairs the acquisition of preference for ethanol. Psychopharmacology 100:350-354

Schulteis G, Martinez JL Jr(1990): ICI 174,864, a selective delta opioid antagonist, reverses the learning impairment produced by [leu]enkephalin. Psychopharmacology 100: 102-109

Schulteis G, Martinez JL Jr (1992a): Peripheral modulation of learning and memory: Enkephalins as a model system. Psychopharmacology 109:347-364

Schulteis G, Martinez JL Jr (1992b): [Leu]enkephalin and its metabolite, Tyr-Gly-Gly, impair active avoidance retention. Pharmacol Biochem Behav 42:523-527

Schulteis G, Martinez JL Jr, Hruby VJ (1988): Stimulation and antagonism of opioid delta-receptors produce opposite effects on active avoidance conditioning in mice. Behav Neurosci 102:678-686

Schulteis G, Janak PH, Derrick BE, Martinez JL Jr (1990): Endogenous opioid peptides and learning and memory. In Szekely JI, Ramabadran K (eds), Opioid Peptides Volume IV: Biochemistry and Applied Physiology. Boca Raton, CRC Press, pp 189-219

Schultzberg M, Lundberg JM, Hökfelt T, Terenius L, Brandt J, Elde RP, Goldstein M (1978): Enkephalin-like immunoreactivity in gland cells and nerve terminals of the adrenal medulla. Neuroscience 3:1169-1186

Weinberger SB, Gehrig CA, Martinez JL Jr (1989): Dpen2[DPen5]enkephalin, a delta opioid receptor-selective analog of [Leu]enkephalin, impairs avoidance learning in an automated shelf-jump task in rats. Reg Pept 26:323-329

Zhang S-Y, McGaugh JL, Juler RG, Introini-Collison IB (1987): Naloxone and [met]enkephalin effects on retention: Attenuation by adrenal denervation. Eur J Pharmacol 138:37-44 